\title{
Hindsight is 2020? Lessons in global health governance one year into the pandemic
}

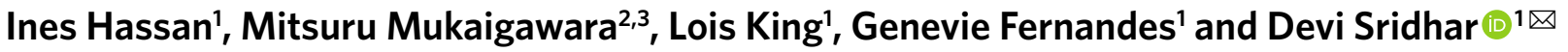

\begin{abstract}
Fourteen months into the SARS-CoV-2 pandemic, we identify key lessons in the global and national responses to the pandemic. The World Health Organization has played a pivotal technical, normative and coordinating role, but has been constrained by its lack of authority over sovereign member states. Many governments also mistakenly attempted to manage COVID-19 like influenza, resulting in repeated lockdowns, high excess morbidity and mortality, and poor economic recovery. Despite the incredible speed of the development and approval of effective and safe vaccines, the emergence of new SARS-CoV-2 variants means that all countries will have to rely on a globally coordinated public health effort for several years to defeat this pandemic.
\end{abstract}

t has now been just over one year since the first two cases of coronavirus disease 2019 (COVID-19) were confirmed in two Chinese nationals staying at a hotel in York, England, on 31 January 2020 (ref. ${ }^{1}$ ). On 26 January 2021, the death toll from COVID-19 in the United Kingdom had surpassed 100,000 and there were reportedly over 30,000 daily cases of the disease, with an estimated 1 in 10 people going on to experience the enduring effects of 'long COVID' (Official UK Coronavirus Dashboard, https://coronavirus.data.gov. uk/details/deaths). The global death toll has just reached 2.1 million (World Health Organization (WHO) COVID-19 Dashboard, https://covid19.who.int). The global death toll had reached almost 2.5 million by 23 February 2021.

However, around the world, a varied picture has emerged (https:// covid19. who.int and refs. ${ }^{2,3}$ ). Countries such as China, Taiwan, New Zealand and Australia have managed to eliminate or get close to elimination of their epidemics caused by severe acute respiratory syndrome coronavirus 2 (SARS-CoV-2) relatively well ${ }^{2,3}$. Others such as Hong Kong, South Korea, Singapore, Finland and Norway have managed to control it at low levels. Sadly, both the United States and the United Kingdom are still battling high numbers of daily cases, tens of thousands of deaths, and an exhausted health workforce and overstretched health services ${ }^{4,5}$.

As the virus proliferated across the globe, it also revealed critical vulnerabilities in our global and national health governance systems that have resulted in inadequate outbreak responses ${ }^{6,7}$. In this Perspective, we explore what is now known about the virus and identify key lessons learned about the WHO and national governance and the impact on pandemic preparedness and response.

\section{What do we know scientifically?}

Since January 2020, a massive surge of research into COVID-19 has enabled the scientific and medical communities to better understand how to manage and ultimately eliminate the virus through pharmaceutical and public health interventions ${ }^{8}$. Among the key findings a year on is that transmission occurs through droplets and aerosols spread through breathing, coughing, speaking and sneezing $^{9}$. Stopping the spread of COVID-19 requires people to avoid mixing through restrictions on social and economic life, as well as a robust test-trace-isolate system and travel restrictions ${ }^{10,11}$.

We have learned that COVID-19 causes more severe symptoms and death in those who are older ${ }^{12}$ and who have underlying health issues (such as cardiovascular disease or obesity) or are immunocompromised (as in those with malignancies or diabetes mellitus) ${ }^{13}$.
We have learned that certain genetic markers can identify individuals more susceptible to respiratory failure ${ }^{14}$.

We have also been learning about the long-term effects of COVID-19, the so-called long COVID, and the morbidity attached to having this virus ${ }^{15}$. Even after recovery from acute illness caused by COVID-19, some patients continue to experience symptoms such as dyspnea and fatigue for weeks or months ${ }^{15}$. Also, the emergence of hyperinflammatory symptoms in children (multisystem inflammatory syndrome, or MIS-C) was reported to coincide with regional COVID-19 epidemics ${ }^{16}$.

We have learned that immunity lasts at least eight months ${ }^{17}$. We also have three licensed vaccines in the United Kingdom, which are already being rolled out and are effective at reducing the incidence of severe COVID-19, although we do not know how long immunity will last or whether the vaccines stop people from being infectious ${ }^{18}$. We have learned that the virus can mutate into various strains that can be more transmissible, can be more severe in their health outcomes and can possibly evade natural or vaccine-induced immunity to the original SARS-CoV-2 virus, requiring governments to plan for a cat-and-mouse game between vaccines and variants ${ }^{19}$.

\section{The role of the WHO}

This pandemic has highlighted the interdependence of countries like never before and, most importantly, the need for a globally coordinated governance response ${ }^{20}$. As countries attempted to respond to COVID-19 outbreaks, the WHO was thrust into the spotlight as many countries looked to it for leadership and guidance ${ }^{21}$. In the process, it has faced inevitable criticism from various stakeholders. This criticism has unveiled-not for the first time-some misinterpretation of the WHO's mandate, its authority, or the lack thereof, over its member states and a number of organizational and legal instrument constraints that have impacted pandemic preparedness and response $\mathrm{e}^{6,22-24}$. The WHO has three key roles in addressing health emergencies: coordination, normative guidance and technical steering ${ }^{25}$.

As the only organization in the United Nations (UN) focused on health, the WHO has a mandate to be "the directing and coordinating authority on international health work" (ref. ${ }^{25}$ ). During the COVID-19 outbreak, it convened the seventy-third World Health Assembly, in which a resolution was adopted to bring the world together to fight the pandemic. The WHO has called for equitable access to all essential health products, such as vaccines, tests and treatments, through the Access to COVID-19 Tools (ACT)

'Global Health Governance Programme, Edinburgh Medical School, University of Edinburgh, Edinburgh, UK. ${ }^{2}$ Harvard Kennedy School, Cambridge, MA,

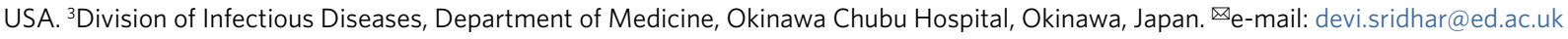



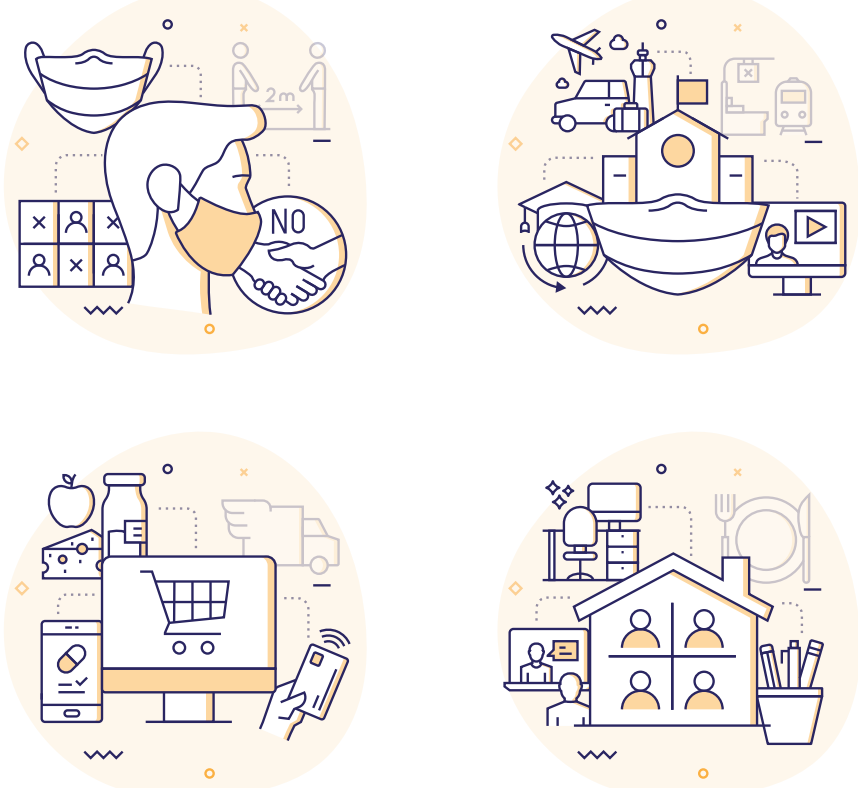

Credit: Designer/DigitalVision Vectors/Getty

Accelerator (https://www.who.int/initiatives/act-accelerator). The WHO has also assembled the COVAX Facility as the vaccine pillar of the ACT Accelerator with other global actors, a mechanism designed to ensure timely access to a diverse set of vaccines for at least $20 \%$ of countries' populations, and the COVID-19 Technology Access Pool (C-TAP), a platform to share patent-protected trial data on emerging treatments ${ }^{26}$. There has been some success: to date, two billion doses of approved and pipeline vaccines have been pledged by wealthy nations, the European Union Commission and the Bill and Melinda Gates Foundation, among others ${ }^{27}$. However, as of January 2021, while vaccine rollout is fully underway in many wealthy nations such as the United Kingdom and the United States, no COVID-19 vaccines have been administered on the continent of Africa and in other low- and middle-income countries ${ }^{28}$. This highlights the limited accountability of COVAX participants and perhaps inefficient incentives for wealthy nations, which have secured in some cases more doses than required to protect their populations (refs. ${ }^{29,30}$ and Our World in Data, https:// ourworldindata.org/covid-vaccinations). Furthermore, by January 2021, C-TAP had attracted zero contributions, nine months after its launch ${ }^{30}$.

Through the International Health Regulations (IHR; last revised in 2005), the WHO also has a "central and historic responsibility" to manage the "global regime for the control of the international spread of disease" (ref. ${ }^{31}$ ). In its normative role, it has the "power to shape or influence global rules and norms and to monitor compliance" (ref. ${ }^{32}$ ). It has arguably fulfilled a large part of this role by providing state-endorsed guidance and by setting norms and standards on outbreak preparedness and response, which include making use of measures such as border controls, identification of cases, prioritization of testing, contact tracing and isolation of carriers of the virus and their contacts, among other interventions ${ }^{31}$. Critically, this guidance ensured that China reported the presence of a novel pathogen on 30 December 2019 and enabled the WHO to declare a Public Health Emergency of International Concern (PHEIC) - the highest level of alert-one month later on 30 January 2020, notably 111 days before the UN Security Council adopted a resolution stating that the COVID-19 pandemic threatened international peace and security ${ }^{26,33}$. Four days after adoption of this resolution, the
WHO published a global strategy to tackle the pandemic, much of which remains valid today ${ }^{26}$.

Moreover, within its technical capacity, it was able to send an international team on mission to China in February 2020 to collect key data on how the virus was spreading and the emerging disease profile as well as lessons learned from policy responses in China up to that point ${ }^{34}$, invaluable knowledge that was shared with the rest of the world in the same month. Furthermore, through its technical role, the WHO has provided daily press briefings on a variety of scientific and policy topics, including up-to-date epidemiology data, the nature of SARS-CoV-2 transmission and appropriate non-pharmaceutical intervention guidance, since it declared a PHEIC (https://www.who.int/emergencies/diseases/ novel-coronavirus-2019/media-resources/press-briefings).

However, there was some criticism that the PHEIC should have been called earlier and that the WHO's diplomatic, but perhaps opaque, approach in working with China to investigate the source of the outbreak and rapidly share information demonstrated a lack of authority over member states ${ }^{6}$. This was further publicized as a result of the Trump administration's threat to withdraw from the $\mathrm{WHO}^{35}$. However, the IHR only afford the WHO normative power, a 'soft' power that relies on the cooperation of member states and cannot be legally enforced ${ }^{32}$. Throughout the pandemic, the WHO has struggled with country cooperation, namely because it does not have an official operational role in outbreak response ${ }^{36}$. This has also been demonstrated in the failure of notable countries such as the United Kingdom and the United States to implement some of the WHO's key public health guidance, such as 'testing, testing, testing', the provision of personal protective equipment and the ramping up of hospital capacity ${ }^{37}$.

Furthermore, although the WHO's technical capabilities during the pandemic are mostly to be lauded, it was slow to offer some key recommendations, namely, on the potential risk of airborne transmission of SARS-CoV-2 under special circumstances (enclosed spaces, prolonged exposure and inadequate ventilation ${ }^{38}$ ), the important role that masks ${ }^{39}$ have in preventing transmission and the use of border controls. History has shown us that the risk of doing nothing while waiting for perfect data outweighs the risk of acting quickly with imperfect data. As Mike Ryan, the executive director of the WHO's Health Emergencies Programme, said in a press conference on 13 March 2020, "Be fast-have no regrets [...] perfection is the enemy of the good when it comes to emergency management. Speed trumps perfection" (https://twitter.com/ SkyNews/status/1238504143104421888). Another technical area where it fell short was that its preparedness metrics (WHO Joint External Evaluation (JEE) mission reports, http://www.who.int/ ihr/procedures/mission-reports/en/) seemingly did not account for variations in country leadership and political will, which have clearly had a big impact on the way countries have responded to the pandemic. Also, it did not sufficiently focus on policies to minimize the increase in social, racial and health inequalities resulting from outbreaks ${ }^{31}$. One major factor that has an impact on all of these coordination, normative and technical shortcomings is the limited funding available to the WHO to operate optimally ${ }^{40}$. Critically, it has been suggested that the health and economic fallout of this unprecedented pandemic may spur new opportunities for more stable funding that might result in transformational change ${ }^{41}$.

\section{National governance: best practice}

By the end of March 2020, almost all countries around the world had introduced nationwidepublichealth measuresaimed at containing the spread of SARS-CoV-2 (Coronavirus Government Response Tracker, https://www.bsg.ox.ac.uk/research/research-projects/coronavirusgovernment-response-tracker). However, the measures used and, subsequently, the health and economic outcomes of the response varied drastically ${ }^{42}$. This variation in response seems to reflect past 
experience in managing infectious disease outbreaks, societal values, long-term investment in healthcare and, critically, the political will of the government in power.

Overall strategic differences. In Europe and the United States, a combination of mitigation and suppression strategies has largely been used at various points in time. This is despite the WHO advising countries to follow the model of elimination from February 2020 (ref. ${ }^{43}$ ). The United Kingdom's initial strategy was based largely on the response to pandemic flu, and government communications made several mentions of mild flu and cold-like symptoms as a result of COVID-19 for the majority of the population ${ }^{44}$. Elimination of the virus was touted as impossible, with the best course of action being to shield the vulnerable as the virus made its way through the population, to avoid overwhelming health services in an attempt to achieve so-called 'herd immunity' (ref. ${ }^{45}$ ). While the successful use of measures such as social distancing and home isolation in China was noted by government advisors, these measures were perceived as postponing the inevitable ${ }^{46}$. The overreliance on the flu model painted an inaccurate picture of how COVID-19 is transmitted: as COVID-19 is more contagious than the influenza virus, it leads to super-spreader events in crowded places. This initial stance evolved into a suppression strategy where targeted health interventions have been used to reduce COVID-19 cases to 'acceptable' levels, for example, by implementing mass testing, lockdowns and the use of masks in indoor public spaces ${ }^{47}$. In contrast, in New Zealand, Taiwan, Vietnam, South Korea, Australia and China, effort was taken to try to rapidly exclude community transmission of the virus using an elimination strategy. As Jacinda Ardern, the prime minister of New Zealand, recently said, even if elimination is not achieved, the approach "will result in a reduction of lives lost in the process" (https://www.facebook.com/deutschewellenews/videos/236469201156575/). As the world has witnessed a return to almost normalcy-at least within national borders-in countries that chose an elimination approach, there appears to be greater enthusiasm to pursue this approach among academics and politicians $^{2}$. In contrast, those who did not follow this approach have succumbed to repeated national lockdowns throughout the year, high mortality rates, long-term health consequences in survivors (including in up to $10 \%$ of survivors in the United Kingdom), indirect health impacts, long-term economic loss and an increase in social and health inequalities ${ }^{48}$.

One factor that has impacted the strategies used by governments is the relatively low case fatality rate (CFR) for COVID-19 of $2 \%$ (ref. ${ }^{49}$ ). The CFRs of severe acute respiratory syndrome (SARS) and Middle East respiratory syndrome (MERS) are much higher than that of COVID-19 at 9-10\% and 36\%, respectively ${ }^{49}$. On the basis of past experience, most countries would have adopted an elimination strategy if the CFR for COVID-19 were higher, because it would have been impossible to let SARS-CoV-2 spread within communities $^{43}$. However, CFR is a deceptive metric on its own because the underlying SARS-CoV-2 virus spreads more easily among people than other viruses with higher CFRs, leading to more cases and therefore more deaths at the population level. Hospitalization rates are a better measure of COVID-19 prevalence because they not only reveal the level of community spread but also provide insight into hospital capacity ${ }^{50}$.

Public health measures. We also now know that effective use of test, trace and isolate (TTI) programs, where infected people and their contacts are rapidly identified and provided financial support to isolate during the incubation period of the virus, along with border controls and efficient and equitable rollout of emerging vaccines, is key to controlling this virus.

In East Asian and Pacific countries, TTI programs, strict border measures and good voluntary public health guidance were central to elimination strategies, allowing these countries to rapidly manage local flare-ups. These measures also resulted in relatively few lockdowns $^{42}$. In Hong Kong, uptake of testing was encouraged by paying people to be tested. Germany also had a relatively lower CFR in comparison to its European counterparts like Italy and the United Kingdom, in part because of its early and broad testing strategy ${ }^{3}$.

The development of vaccines has provided governments with an additional tool to protect their populations. Governments in high-income countries in particular have embarked on mass efforts to roll out vaccine, starting with their most vulnerable groups. By mid-January 2021, Israel had administered the first dose of a two-part vaccine to over $25 \%$ of its population, including to $75 \%$ of those over the age of 60 years. There are early indications that this is having a positive impact, with a reduction from $30 \%$ to $7 \%$ in the occurrence of critical illness in patients in the older age bracket two weeks after vaccination ${ }^{51}$. However, questions remain on the protection provided until the second dose is administered. Additionally, inequitable access, both globally and nationally, is an issue; in Israel, cities of lower socioeconomic status had administered fewer vaccinations than their wealthier counterparts (COVID-19 Maps, https://vaccinations.covid19maps.org/). What is clear is that a fast rollout is essential to stopping hospitalizations and deaths, as well as-eventually-community transmission, ultimately reducing the likelihood that new variants of the SARS-CoV-2 virus will emerge.

Social inequalities. The disproportionate impact that this pandemic has had on vulnerable populations and minority ethnic groups around the world must also not be overlooked ${ }^{52}$. This is typically a result of riskier work and living conditions, limited access to protective wear-and in some countries treatments-and limited availability of financial protection to ensure that key public health measures such as isolation and distancing can be implemented ${ }^{52}$. Governments have learned, often as a result of a public outcry, that identifying these vulnerable groups quickly and implementing tailored interventions to reduce the risk of infection in these groups is critical. For example, in Hong Kong, people were paid to encourage testing, while in the United Kingdom mass testing was eventually introduced in care homes as a way to rapidly identify and isolate cases $^{53,54}$.

Other key lessons are that elimination is achievable if swift political commitment is made early on in an outbreak and that, by accepting short-term stringent public health measures, viral community transmission is reduced, fewer COVID-19 cases are detected and economic loss is minimized ${ }^{2}$. At the global level, however, we should also recognize that not every country is able to implement the same public health measures. Countries such as Japan could not legally enforce strict containment measures because of their infringement on human rights ${ }^{55}$. Furthermore, in Nigeria, political disorder and aggressive use of force by the police to limit protests intensified when strict public health interventions were enforced ${ }^{56}$.

Leadership and communication. Clear and evidence-based communication during an outbreak is critical to build trust with the public and to ensure adherence to public health measures and successful containment. Most importantly, a government's concept of a successful outcome and the strategy used to achieve it need to be well defined ${ }^{57}$. Some leaders seem to have managed clear communication, for example, in New Zealand, South Korea, Scotland, Taiwan and Senegal, while others have struggled, for example, in the United States and the United Kingdom. As the pandemic has unfolded, knowledge about the virus, how to manage it and the interventions available to us has rapidly evolved. Some governments have been good at communicating uncertainty and necessary changes in strategy when better options have become clear. For instance, in New Zealand, after the PHEIC was declared by the WHO, the government communicated that an elimination strategy was being adopted ${ }^{58}$. 
In the United States and the United Kingdom, it has at times been unclear what success would look like, how this would be measured and what approach was being adopted: exclusion, elimination, suppression or containment of the virus ${ }^{2}$. In the United States, the Trump administration regularly ignored scientific evidence and the federal government "largely abandoned disease control to the states" (ref. ${ }^{59}$ ), resulting in a massive failure in handling COVID19. In the United Kingdom, questions about changes were often met with protestations of having 'world-beating' approaches, a symptom of the UK exceptionalism that underestimated the virus in the first place ${ }^{60}$. Moreover, some government ministers in the United Kingdom recently announced that National Health Service (NHS) hospitals were full because the public was not adhering to public health measures ${ }^{61}$. Shifting responsibility to individuals alone through such disparaging messaging can lead to a lack of compliance with government rules.

Economy versus health. Throughout the pandemic, a false dichotomy pitting public health against economic success has emerged ${ }^{62}$. In fact, one common argument against stringent public health measures like lockdowns is the potential damage such measures could inflict on the national economy. It is incorrect that loss of economic growth and job losses are a primary consequence of social distancing measures rather than the virus itself ${ }^{62}$. Not taking strict public health measures to prevent harm to the national economy during the pandemic is a short-sighted policy; in the long run, a brief closure and temporary subsidization have proven to be more cost-beneficial than keeping the economy open. Although New Zealand experienced an annual contraction in real gross domestic product (GDP) of $6.1 \%$, this is much lower than the decrease seen in other comparable countries, and in Taiwan the net GDP was $0 \%$ (ref. ${ }^{63}$ ). Furthermore, economists argue that the estimated economic cost of the pandemic in the United States has been US\$16 trillion ${ }^{64}$. Effective public health measures, if implemented, can reduce these financial costs significantly. Contrary to the false-yet commonly cited-dichotomy, protecting the health of the people is equivalent to protecting the wealth of the people. Similar analyses have shown that this was also the case in the 1918 influenza pandemic ${ }^{65}$.

\section{Conclusion}

Looking ahead to year two of the pandemic, our collective progress will be dependent on a coordinated global effort to leave no one behind. Although the mass vaccination rollout will dominate COVID-19 policy this year, the emergence of new SARS-CoV-2 variants that may escape the body's neutralizing antibody response and continued inequitable access to vaccines indicate that the COVID-19 pandemic will continue. This may well turn out to be the year of variants and vaccines. However, now we are armed with knowing what works, what does not and the range of interventions needed to keep case numbers low. Let us fix our fragmented global health system and follow the elimination playbook together because, if we have learned anything this past year, it is that, globally, we are only as strong as our weakest link.

Received: 28 January 2021; Accepted: 28 January 2021; Published online: 15 March 2021

\section{References}

1. Gallagher, J. Coronavirus: Two cases confirmed in UK. BBC News https://www.bbc.com/news/health-51325192 (31 January 2020).

2. Baker, M. G., Wilson, N. \& Blakely, T. Elimination could be the optimal response strategy for covid-19 and other emerging pandemic diseases. BMJ 371, m4907 (2020)

3. Lu, G. et al. COVID-19 in Germany and China: mitigation versus elimination strategy. Glob. Health Action 14, 1875601 (2021).

4. UK data on hospital capacity and occupancy. Office for Statistics Regulation. https://osr.statisticsauthority.gov.uk/news/uk-data-on-hospital-capacity-andoccupancy/ (OSR, 2020).
5. Department of Health \& Human Services. COVID-19 reported patient impact and hospital capacity by facility. HealthData.gov https://healthdata. gov/dataset/covid-19-reported-patient-impact-and-hospital-capacity-facility (2021).

6. Independent Panel for Pandemic Preparedness and Response. Second report on progress. https://theindependentpanel.org/wp-content/uploads/2021/01/ Independent-Panel_Second-Report-on-Progress_Final-15-Jan-2021.pdf (2021).

7. Legge, D. G. COVID-19 response exposes deep flaws in global health governance. Glob. Soc. Policy 20, 383-387 (2020).

8. Kupferschmidt, K. A divisive disease. Science 370, 1395-1397 (2020).

9. Ma, J. et al. COVID-19 patients in earlier stages exhaled millions of SARSCoV-2 per hour. Clin. Infect. Dis. https://doi.org/10.1093/cid/ciaal283 (2020).

10. Centers for Disease Control and Prevention. How to protect yourself \& others. https://www.cdc.gov/coronavirus/2019-ncov/prevent-getting-sick/ prevention.html (2020).

11. World Health Organization. Transmission of SARS-CoV-2: implications for infection prevention precautions. https://www.who.int/news-room/ commentaries/detail/transmission-of-sars-cov-2-implications-for-infectionprevention-precautions (2020).

12. Williamson, E. J. et al. Factors associated with COVID-19-related death using OpenSAFELY. Nature 584, 430-436 (2020).

13. Berlin, D. A., Gulick, R. M. \& Martinez, F. J. Severe Covid-19. N. Engl. J. Med. 383, 2451-2460 (2020).

14. Severe Covid-19 GWAS Group et al. Genomewide association study of severe Covid-19 with respiratory failure. N. Engl. J. Med. 383, 1522-1534 (2020).

15. Centers for Disease Control and Prevention. Long-term effects of COVID-19. https://www.cdc.gov/coronavirus/2019-ncov/long-term-effects.html (2020).

16. Feldstein, L. R. et al. Multisystem inflammatory syndrome in U.S. children and adolescents. N. Engl. J. Med. 383, 334-346 (2020).

17. Dan, J. M. et al. Immunological memory to SARS-CoV-2 assessed for up to 8 months after infection. Science https://doi.org/10.1126/science.abf4063 (2021).

18. Callaway, E. Could new COVID variants undermine vaccines? Labs scramble to find out. Nature 589, 177-178 (2021).

19. Joseph, A. Scientists monitor a coronavirus mutation that could affect vaccine strength. STAT https://www.statnews.com/2021/01/07/coronavirus-mutationvaccine-strength/ (7 January 2021).

20. Kayo, T. Global solidarity is necessary to end the COVID-19 pandemic. Asia-Pac. Rev. 27, 46-56 (2020).

21. Kuznetsova, L. COVID-19: The world community expects the World Health Organization to play a stronger leadership and coordination role in pandemics control. Front. Public Health 8, 470 (2020).

22. Phelan, A. L. \& Katz, R. Governance preparedness: initial lessons from COVID-19. https://apps.who.int/gpmb/assets/thematic_papers_2020/ tp_2020_1.pdf (Center for Global Health Science \& Security, Georgetown University, 2020).

23. Richardson, J., Wildman, J. \& Robertson, I. K. A critique of the World Health Organisation's evaluation of health system performance. Health Econ. 12, 355-366 (2003).

24. Gilsinan, K. How China deceived the WHO. The Atlantic https://www. theatlantic.com/politics/archive/2020/04/world-health-organization-blamepandemic-coronavirus/609820/ (12 April 2020).

25. World Health Organization. Constitution of the World Health Organization (World Health Organization, 1946).

26. World Health Organization. Listings of WHO's response to COVID-19. https://www.who.int/news/item/29-06-2020-covidtimeline (2020).

27. World Health Organization. COVAX announces additional deals to access promising COVID-19 vaccine candidates; plans global rollout starting Q1 2021. Press release. https://www.who.int/news/item/18-12-2020-covax-announ ces-additional-deals-to-access-promising-covid-19-vaccine-candidates-plansglobal-rollout-starting-q1-2021 (18 December 2020).

28. Soy, A. Africa's long wait for the Covid-19 vaccine. BBC News https://www. bbc.com/news/world-africa-55751714 (22 January 2021).

29. OXFAM International. Campaigners warn that 9 out of 10 people in poor countries are set to miss out on COVID-19 vaccine next year. Press release. https://www.oxfam.org/en/press-releases/campaigners-warn9-out-10-people-poor-countries-are-set-miss-out-covid-19-vaccine (9 December 2020).

30. Safi, M. WHO platform for pharmaceutical firms unused since pandemic began. The Guardian http://www.theguardian.com/world/2021/jan/22/ who-platform-for-pharmaceutical-firms-unused-since-pandemic-began (22 January 2021).

31. World Health Organization. International Health Regulations (World Health Organization, 2005).

32. Gostin, L. O., Sridhar, D. \& Hougendobler, D. The normative authority of the World Health Organization. Public Health 129, 854-863 (2015).

33. United Nations Meetings Coverage and Press Releases. Security Council underlines support for Secretary-General's global ceasefire appeal, fight against COVID-19, unanimously adopting resolution 2532 (2020). Press release. https://www.un.org/press/en/2020/sc14238.doc.htm (1 July 2020). 
34. World Health Organization. Report of the WHO-China Joint Mission on Coronavirus Disease 2019 (COVID-19). https://www.who.int/docs/defaultsource/coronaviruse/who-china-joint-mission-on-covid-19-final-report.pdf (2020).

35. Remarks by President Trump on actions against China, May 29, 2020. https:// china.usc.edu/remarks-president-trump-actions-against-china-may-29-2020 (USC US-China Institute, 29 May 2020).

36. Wenham, C. What we have learnt about the World Health Organization from the Ebola outbreak. Philos. Trans. R. Soc. B Biol. Sci. 372, 20160307 (2017).

37. Scally, G., Jacobson, B. \& Abbasi, K. The UK's public health response to covid-19. BMJ 369, m1932 (2020).

38. Centers for Disease Control and Prevention. Scientific Brief: SARS-CoV-2 and potential airborne transmission. https://www.cdc.gov/coronavirus/2019ncov/more/scientific-brief-sars-cov-2.html (2020).

39. Brooks, J. T., Butler, J. C. \& Redfield, R. R. Universal masking to prevent SARS-CoV-2 transmission-the time is now. JAMA https://doi.org/10.1001/ jama.2020.13107 (2020).

40. Clinton, C. \& Sridhar, D. Who pays for cooperation in global health? A comparative analysis of WHO, the World Bank, the Global Fund to Fight HIV/AIDS, Tuberculosis and Malaria, and Gavi, the Vaccine Alliance. Lancet 390, 324-332 (2017).

41. Gostin, L. O. COVID-19 reveals urgent need to strengthen the World Health Organization. JAMA 323, 2361-2362 (2020).

42. Han, E. et al. Lessons learnt from easing COVID-19 restrictions: an analysis of countries and regions in Asia Pacific and Europe. Lancet 396, 1525-1534 (2020).

43. Sridhar, D. COVID-19: what health experts could and could not predict. Nat. Med. 26, 1812 (2020).

44. Emergency and Health Protection Directorate. Coronavirus: action plan. A guide to what you can expect across the UK. https://assets.publishing.service. gov.uk/government/uploads/system/uploads/attachment_data/file/869827/ Coronavirus_action_plan_-_a_guide_to_what_you_can_expect_across_the UK.pdf (2020)

45. Horton, R. Offline: COVID-19—a reckoning. Lancet 395, 935 (2020).

46. Kaminska, I. Making sense of nonsensical Covid-19 strategy. Financial Times https://www.ft.com/content/662a0033-61eb-4b1f-b95c-855a9ef8061f (2 June 2020).

47. Cameron-Blake, E. et al. Variation in the response to COVID-19 across the four nations of the United Kingdom. Blavatnik School Working Paper https://www.bsg.ox.ac.uk/research/publications/variation-response-covid19-across-four-nations-united-kingdom (Univ. Oxford, 2020).

48. Greenhalgh, T., Knight, M., A'Court, C., Buxton, M. \& Husain, L. Management of post-acute covid-19 in primary care. BMJ 370, m3026 (2020).

49. Fauci, A. S., Lane, H. C. \& Redfield, R. R. Covid-19-navigating the uncharted. N. Engl. J. Med. 382, 1268-1269 (2020).

50. Lehmann, C. Many metrics to measure COVID-19, which are best? WebMD https://www.webmd.com/lung/news/20200922/many-metrics-to-measurecovid-19-which-are-best (2020).

51. Covid-19 vaccines-how fast can vaccination against covid-19 make a difference? The Economist https://www.economist.com/science-andtechnology/2021/01/23/how-fast-can-vaccination-against-covid-19-make-adifference (23 January 2021).

52. Trout, L. J. \& Kleinman, A. Covid-19 requires a social medicine response. Front. Sociol. https://doi.org/10.3389/fsoc.2020.579991 (2020).

53. Albeck-Ripka, L. Hong Kong seeks to encourage testing with cash payments. The New York Times https://www.nytimes.com/2020/11/23/world/hong-kongseeks-to-encourage-testing-with-cash-payments.html (23 November 2020).
54. Department of Health and Social Care. Government launches new portal for care homes to arrange coronavirus testing. Press release. https://www.gov. $\mathrm{uk} /$ government/news/government-launches-new-portal-for-care-homes-toarrange-coronavirus-testing (11 May 2020).

55. Yamaguchi, M. Japan's state of emergency is no lockdown. What's in it? AP News https://apnews.com/article/eb73f1170268ec2cdcf03e697365acb2 (8 April 2020)

56. Pavlik, M. A great and sudden change: the global political violence landscape before and after the COVID-19 pandemic. https://acleddata.com/2020/08/04/a great-and-sudden-change-the-global-political-violence-landscape-before-andafter-the-covid-19-pandemic/ (Armed Conflict Location \& Event Data Project, 2020)

57. Tworek, H., Beacock, I. \& Ojo, E. Democratic health communications during Covid-19: a RAPID response. https://democracy.arts.ubc.ca/2020/09/14/ covid-19/ (Centre for the Study of Democratic Institutions, University of British Columbia, 2020)

58. Jefferies, S. et al. COVID-19 in New Zealand and the impact of the national response: a descriptive epidemiological study. Lancet Public Health 5, e612-e623 (2020)

59. Editors. Dying in a leadership vacuum. N. Engl. J. Med. 383, 1479-1480 (2020)

60. Paton, C. World-beating? Testing Britain's Covid response and tracing the explanation. Health Econ. Policy Law https://doi.org/10.1017/S17441331 2000033X (2020).

61. Vaughan, R. Priti Patel blames minority of Covid-19 rule breakers for putting 'health of nation at risk'. MSN https://www.msn.com/en-gb/news/world/ priti-patel-blames-minority-of-covid-19-rule-breakers-for-putting-health-of-n ation-at-risk/ar-BB1cHaOB (12 January 2021).

62. Summers, L. H. Opinion: Trump is missing the big picture on the economy. Washington Post https://www.washingtonpost.com/opinions/2020/03/24/ trump-is-missing-big-picture-economy/ (24 March 2020).

63. International Monetary Fund. World Economic Outlook: A Long and Difficult Ascent (International Monetary Fund, 2020)

64. Cutler, D. M. \& Summers, L. H. The COVID-19 pandemic and the \$16 trillion virus. JAMA 324, 1495-1496 (2020).

65. Correia, S., Luck, S. \& Verner, E. Pandemics depress the economy, public health interventions do not: evidence from the 1918 flu. Preprint at SSRN https://doi.org/10.2139/ssrn.3561560 (2020).

\section{Author contributions}

D.S. and I.H. conceptualized the piece. D.S., I.H. and M.M. drafted the first version of the manuscript. L.K. and G.F. commented on and edited the draft. All authors reviewed and agreed with the final version.

\section{Competing interests}

D.S. advises the UK and Scottish Governments and receives research funding for her team from the Wellcome Trust. The other authors declare no competing interests.

\section{Additional information}

Correspondence should be addressed to D.S.

Peer review information Marianne Guenot was the primary editor on this article and managed its editorial process and peer review in collaboration with the rest of the editorial team.

Reprints and permissions information is available at www.nature.com/reprints. Publisher's note Springer Nature remains neutral with regard to jurisdictional claims in published maps and institutional affiliations.

(C) Springer Nature America, Inc. 2021 